\title{
EMPIRISMO E FISICALISMO: CARACTERÍSTICAS DO HOLISMO EPISTEMOLÓGICO DE WILLARD QUINE
}

Sofia Inês Albornoz Stein

U niversidade Federal de Goiás

siastein@uol.com.br

RESU M 0: 0 presente artigo disserta sobre duas características centrais ao holismo epistemológico de W illard Q uine: a sustentação de critérios empíricos de avaliação por meio das senten ças observacionais e a defesa de que a ontologia fisicalista é decisiva para a avaliação de teorias.

Pal avras-chave: Q uine, empirismo, fisicalismo, epistemologia, ontologia.

\section{INTRODUÇÃO}

Todo o sistema filosófico de Q uine pode ser compreendido como uma tentativa de explicar o funcionamento interno da linguagem significativa, utilizando para tanto a própria linguagem significativa. Romper com essa circularidade inerenteà toda filosofia pode ser a pretensão de muitos sistemas filosóficos, porém não é a pretensão de Q uine. Em seu artigo "Q uine in perspective", R ichard Schuldenfrei escreve:

Q uine não pensa ter encontrado um ponto arquimediano a partir do qual se pode filosofar acerca do resto do mundo. Ele está filosofando sobre o mundo como um todo, incluindo Quine e sua epistemologia. [...] A experiência confiável nos diz qual teoria é correta, e as teorias nos dizem quais dados são confiáveis. A circularidade, ou o potencial para ela, constrói-se nessa concepção de evidência. ${ }^{1}$ 
Segundo Schuldenfrei, a noção de evidência que, nos escritos de Q uine, serve de base às teorias científicas, é a mesma noção que permite verificar algumas afirmações da epistemologia naturalizada assumida por Quine como posição filosófica aceitável. Assim, a filosofia de Q uine pretende estar no mesmo nível de conhecimento das outras ciências e preten de poder ser refutada da mesma maneira que estas. Se quisermos, então, refutar o sistema filosófico de Q uine, não basta achar falhas de argumentação ou exemplos falhos. D evemos, isto sim, tentar substituir o sistema filosófico em questão por um sistema que explique de forma mais satisfatória os objetos tratados; no caso específico de Q uine, a linguagem significativa e suas diversas funções. Por fim, Schuldenfrei chega a comparar 0 método de Q uine ao método hegeliano:

0 argumento não é simplesmente circular, mas algo muito mais complicado. Ao argumentar a favor da divisão entre uma ciência aceitável e uma ciência do especificamente mental, Quine está fazendo uma epistemologia científica, e o epistemologista científico tem a si próprio como uma parte de seu assunto - de fato, sua epistemologia é parte de seu assunto. A ssim, em certo sentido, o argumento de Q uine não tem duas partes mais do que tem uma. $E$, mais do que pela metáfora do círculo bidimensional, o argumento de Quine parece mais bem descrito pela analogia com 0 absoluto se tornando consciente de si mesmo de Hegel. ${ }^{2}$

Porém não é fácil compreender a visão que Q uine tem das ciências em geral e de suas evidências. A pesar de poder parecer, à primeira vista, que a própria teoria determina quais evidências confirmam-na, essa mesma teoria deve ser avaliada por seu poder explicativo, por sua simplicidade etc., ou seja, por critérios pragmáticos, Q uine não esgota sua análise da verdade de teorias científicas na análise desses critérios. Preserva-se, no interior de sua epistemologia, a pretensão empirista de mostrar quais seriam as evidências empíricas de uma determinada teoria ou, dito de outra maneira, 
qual seria a base de sustentação empírica de teorias científicas e qual seria a relação entre a teoria e sua base empírica.

\section{A BASE EMPÍRICA}

Seguindo o raciocínio, por exemplo, de C hristopher Boorse, a epistemologia naturalizada seria incompatível com a semântica e com a tese da indeterminação da tradução sustentadas por Q uine. Segundo Boorse, a tentativa de Quine de diferenciar entre sentenças observacionais e sentenças teóricas significa um retrocesso ao reducionismo criticado por ele em "Two dogmas of empiricism". A suposição de Q uine de que existem e devem existir sentenças que podem ser aprendidas por pura ostensão e cujo conteúdo provém exclusivamente de estímulos sensoriais preserva, segundo Boorse, o mito empirista da relação direta, não-mediada, entre certas sentenças e as experiências sensoriais:

O engano está em supor que uma sentença gramaticalmente complexa pode ser compreendida sem a compreensão de pelo menos algumas outras sentenças. Este ponto faz com que a tese de Quine se torne implausível se aplicada à maioria das sentenças observacionais; e eu penso que isto afeta igualmente os exemplos de uma palavra só. Se "coelho" é uma sentença do inglês, é certamente uma abreviação de "Há um coelho" ou "Aquilo é um coelho". Essas expansões tornam explícita a ocorrência oculta do termo. Se compreender o termo "coelho" requer a "teoria da permanência dos corpos", então a criança aprendiz não entende essa primeira sentença de observação até ter compreendido a teoria. ${ }^{3}$

Essa divisão entre sentenças observacionais e sentenças teóricas, além de parecer contradizer a visão holista de um universo de linguagem significativa, tem como conseqüência uma visão inusitada das teorias científicas. Essa visão estabelece dois diferentes tipos de critérios de avaliação de teorias: um tipo de critério empírico 
e um tipo de critério não-observacional ou pragmático. A conjugação de critérios observacionais e não-observacionais traz consigo, segundo Boorse, uma exposição inconsistente da avaliação da verdade de teorias científicas:

Q uando ele [Q uine] observa o que os cientistas realmente fazem, a sua análise do método científico tende a justificar 0 holismo original de "Dois dogmas". N esse contexto, ele sustenta repetidamente que a distinção observação/ teoria é uma diferença de grau - na expressão de Rorty de que "teorias descem todo o caminho" ("Indeterminacy of Translation and of Truth", 450) - e enfatiza a maneira pela qual cânones nãoobservacionais impregnam a fábrica de crenças. Mas essas conclusões violentam a sua consciência; assim, ao final, quando 0 assunto muda de epistemologia para semântica, o mundo de Quine repentinamente parece muito diferente. R esumindo: sentenças de observação são as únicas a ter "um conteúdo empírico absolutamente próprio", que é perfeitamente capturado pela representação de stimulus-meaning. De maneira geral, elas têm de enfrentar o tribunal dos sentidos sozinhas. A metamorfose é completa quando, no final, como acabamos de ver, as teorias rivais que nossos cânones não-observacionais têm como tarefa discriminar revelam-se afinal sinônimas. ${ }^{4}$

Assim, segundo Boorse, se avaliarmos teorias científicas rivais a partir de critérios não-observacionais, devemos ser levados necessariamente a ver essas teorias como teorias diversas que enfrentam de forma diversa os "dados empíricos", ou seja, cada teoria molda suas evidências. Isto equivale a dizer que mesmo as senten ças menos teóricas devem depender, em certo grau, da teoria como um todo. $\mathrm{Se}$, entanto, afirmarmos que teorias rivais podem ser empiricamente equivalentes, apesar de teoricamente diversas, aceitamos o fato de teorias diversas poderem ser sinônimas com relação ao seu conteúdo significativo, que, em Q uine, equivale ao conteúdo empírico. E isso, por sua vez, significa afirmar que a elaboração teórica não determina absolutamente a relação entre as sentenças e as evidências. 
Paul A. Roth, em seu artigo "Paradox and indeterminacy", contrapõese à crítica de Boorse a Q uine. Roth defende a importância das noções de sentença observacional e de stimulusmeaning por enten der serem noções essenciais à compreen são de como ocorre 0 aprendizado de uma linguagem. Essas sentenças observacionais seriam, segundo Roth, a base inicial para a concordância intersubjetiva em relacionar palavras a situações estimulatórias compartilhadas. Permitem explicar a maneira pela qual os homens ingressam no universo significativo de uma linguagem:

Segundo Boorse, nós não podemos corrigir a criança até ela poder nos compreender (ou seja, até ela falar a língua), mas então já é tarde demais. $\mathrm{Na}$ ausência do controle social, é totalmente milagroso que a linguagem se perpetue. Boorse pode achar a noção de sentença de observação estranha, mas não énem de perto tão estranha quanto a visão do aprendizado de uma língua que resulta se prescindirmos da noção. Compreendidas devidamente, as sentenças de observação fornecem a conexão necessária entre a estimulação verbal no interior da teoria e as estimulações que são independentes da teoria. ${ }^{5}$

A defesa que Roth elabora da posição de Q uine, com relação à necessidade de existência de sentenças observacionais, corresponde à própria argumentação de Q uine quando este descreve a função dessas sentenças na linguagem e na ciência. Entretanto, apesar de parecer consideravelmente convincente 0 argumento de que são necessárias portas de en trada para o significado ingressar na linguagem, que seriam as sentenças observacionais, poder-seia imaginar o significado sendo elaborado em sentenças relacionadas sempre apenas mediatamente, através da mediação de outras sentenças às evidências empíricas, ou seja, sem a exigência de uma relação imediata entre certas sentenças observacionais e estímulos sensoriais. Isto é, poderíamos observar o conjunto de sentenças da linguagem significativa sempre em uma conexão mediada com a realidade. Assim também 0 aprendizado de sentenças poderia ser explicado 
pelo aprendizado simultâneo de conjuntos de sentenças interligadas no jogo intersubjetivo de comunicação verbal.

Q uine, portanto, conserva no interior do seu holismo moderado, de uma maneira apaziguada, o dogma empirista do reducionismo:

É através do vocabulário observacional que a linguagem faz 0 seu principal contato com a experiência. É esta a parte da linguagem que aprendemos primeiro a aplicar, e à qual recorremos quando se necessita de um ponto de controle. ${ }^{6}$

\section{FISICALISM 0}

Não é só na sua análise do significado que Quine retoma certas pretensões empiristas. A sua análise da referência de termos a objetos também desemboca em uma visão epistemológica próxima à visão reducionista do positivismo lógico. Ao afirmar que a visão fisicalista seria a mais clara para fazer frente ao problema epistemológico de como nos referimos ao mundo, Q uine volta a introduzir um tipo de primazia da ontologia de objetos físicos sobre outras ontologias possíveis:

0 que está posto como objetos aos quais os termos podem referir serão, primariamente, objetos que são considerados idênticos sob mudanças de perspectiva. Isto explica a primazia dos corpos. Se a clareza pode ser atribuída a coisas assim como a palavras, então corpos são coisas das mais claras. Se a investigação deve começar com o que é claro, então comecemos como fisicalistas. ${ }^{7}$

O s objetos físicos são, portanto, segundo Q uine, aqueles objetos mais familiares ao homem, mais claramente identificáveis e que possibilitam ao cientista aproximar-se da realidade de uma maneira muito satisfatória. Q uine não está propriamente abandonando seu holismo moderado em favor de um realismo dos objetos 
físicos. A proxima-se da posição fisicalista com o intuito de apresentar a visão do mundo que considera a mais competente para explicar os fenômenos naturais.

0 fisicalista não insiste em uma ontologia exclusivamente corpórea. Ele se satisfaz em declarar os corpos como fundamentais para a natureza aproximadamente neste sentido: não há diferença no mundo sem uma diferença na posição ou estado dos corpos. [...] Eu poderia expressar melhor a questão em termos de "mudança": não há mudança sem uma mudança na posição ou estado dos corpos. [...] 0 nde posições e estados dos corpos não importam, não há fatos materiais. ${ }^{8}$

Assumir uma posição fisicalista não significa necessariamente, para $Q$ uine, reduzir toda e qual quer ontologia à ontologia fisicalista. A possibilidade de criar outras ontologias permanece. A propósito, Q uine considera corpos como entidades teóricas, construídas no interior de um sistema lingüístico que procura referir o mundo exterior da melhor maneira possível.

Ele admite a limitação da ontologia fisical ista, que têm corpos como seus objetos, na física moderna, principalmente na física quântica. Ele pretende superar essa limitação via teoria dos conjuntos, utilizando a matemática pura na descrição de pontos espaçotemporais, dos quais são predicados certos estados físicos. O u seja, em vez de elaborarmos uma ontologia fisical ista, fazemos referência ao mundo através de um sistema de coordenadas e de quádruplas de números. Tendo efetivado a referência dessa maneira, podemos atribuir predicados físicos a determinadas regiões delimitadas com o auxílio do sistema de coordenadas e de conjuntos de quádruplas de números.

Qual é agora a afirmação do fisicalismo? Simplesmente que não há diferença em questões de fato sem uma diferença na satisfação dos predicados de estados físicos por regiões espaçotemporais. N ovamente, isto não é reducionismo em um 
sentido forte. Não há a suposição de que qualquer um esteja em uma posição de sugerir o predicado de estado apropriado para as regiões pertinentes em qualquer caso particular. ${ }^{9}$

Quine não descreve nem qual seria o melhor sistema de coordenadas a ser utilizado pela física, nem quais seriam os predicados de estados físicos que melhor serviriam à descrição do mundo. Deixa isto em aberto e enfatiza a possibilidade de construirmos mais de um sistema de coordenadas e mais de um léxico de predicados de estados físicos. Entretanto, seguindo a tradição positivista, chama a esses estados físicos de estados físicos el ementares, que permitiriam descrever a realidade e as mudanças nesta de uma maneira abrangente e detalhada.

Q uestões acerca de fatos são, segundo Quine, questões ontológicas. Todavia nem todas as questões ontológicas são questões de fato, apenas as questões ontológicas que dizem respeito, em última instância, a objetos físicos ou a mudanças em estados físicos. Ao simplesmente reinterpretarmos a ontologia de um outro falante, ou traduzi-la para uma ontologia alternativa, não estamos falando de mudanças em estados físicos, não estamos falando sobre fatos materiais, estamos apenas elaborando uma nova construção significativa possível acerca dos mesmos fatos materiais. "0 sistema científico, a ontologia e tudo, é uma ponte conceptual construída por nós próprios, ligando a estimulação sensorial à estimulação sensorial." 10

Conclusão

0 ponto de partida de Q uine é o ponto de partida dos empiristas tradicionais, isto é, "os receptores sensoriais e os corpos próximos e afastados, cujas emanações afetam nossos receptores" ${ }^{11}$ A maneira como elaboramos a superestrutura lingüística e a nossa ontologia está condicionada apenas à supervisão de nossas terminações nervosas. Se, por meio de nossa teoria científica, fazemos 
predições erradas acerca da realidade, vemo-nos forçados a reestruturar a superestrutura lingüística utilizada. "N ossa teoria científica global exige do mundo somente que ele esteja estruturado de tal maneira que assegure as seqüências de estimulação que nossa teoria nos faz esperar." 12

A epistemologia naturalizada inserese no âmbito das outras ciências como um estudo do método utilizado na composição de sistemas lingüísticos significativos e ontologias. Não será ela que irá fal ar sobre fatos materiais, mas poderá fazer parte da superestrutura de nossa linguagem.

ABSTRACT: This paper examine two characteristic traits of Quine's epistemological holism: the persistence in sustaining empirical criteria as means for evaluation through observational sentences and the defense that a physicalist ontology is central for such an evaluation.

Key words: Q uine, empiricism, fisicalism, epistemology, ontology.

\section{Notes}

1. Schu Ldenfrel, R. Q uinein perspective. The Journal of Philosophy, v. 69, n. 1, p. 15, 1972.

2. Idem, p. 16.

3. BOORSE, C. The origins of the indeterminacy thesis. Journal of Philosophy, v. 79, p. 374, 1975.

4. Idem, p. 387.

5. Rотн, P. A. Paradox and indeterminacy. Journal of Philosophy, v. 75, n. 7, p. 362, 1978.

6. Quine, W. V. O. Facts of the matter. In: Shahan, R.; Swoyer, C. Essays on the philosophy of W. V. Q uine. O klahoma: TheH arvester Press, 1979. p. 158.

7. Idem, p. 159.

8. Idem, p. 162.

9. Idem, p. 166. 
10. Q uine, W. V. O. Things and their place in theories. Theories and things. C ambridge, M assachusetts: Basil Blackwell, 1981. p. 20.

11. Idem, p. 21.

12. Idem, p. 23.

\section{Referêndias}

BOORSE, C. The origins of the indeterminacy thesis. The Journal of Philosophy, 72, p. 369-387. 1975.

Q UINE, W. V. O. Two dogmas of empiricism. From a logical point of view: nine logico-philosophical essays. 2. ed. Cambridge, M assachusetts: H arvard U niversity Press, 1961. p. 20-46. [1. ed. 1951].

. Facts of the matter. In: SHAHAN, R.; Swo yer, C. Essays on the philosophy of W. V. Q uine. O klahoma: The H arvester Press, 1979. p. 155-169.

. Things and their place in theories. Theories and things. Cambridge, M assachusetts: $\mathrm{H}$ arvard U niversity Press, 1981. p. 123.

Rотн, P. A. Paradox and indeterminacy. The Journal of Philosophy, v. 75, n. 7, p. 347-367, 1978.

Schuldenfrel, R. Q uine in perspective. The Journal of Philosophy, v. 69, n. 1, p. 5-16, 1972. 